\title{
CÂNCER DE MAMA: DE PERFIS MOLECULARES A CÉLULAS TRONCO
}

\author{
Juliana Silva ZANETTI BMSc, MsC student ${ }^{*}$ \\ Lucinei Roberto OLIVEIRA DDS, $\mathrm{PhD}^{\dagger}$ \\ Alfredo RIBEIRO-SILVA MD, PhD*
}

\begin{abstract}
RESUMO: O câncer de mama é a neoplasia maligna mais incidente entre a população feminina. A maioria dos tumores de mama são resultados de alterações genéticas e epigenéticas que podem mudar a morfologia e a função das células. A tumorigênese do câncer de mama e sua progressão são resultantes do acúmulo dessas alterações genéticas que leva a transição gradual do tecido normal para o maligno. Além dessas alterações, acredita-se que o câncer pode se originar de uma única célula que adquire a capacidade de se proliferar indefinidamente. Essas células compartilham algumas características com as células tronco do tecido adulto normal, por isso muitas vezes são denominadas células tronco tumorais. Estudos recentes correlacionaram a expressão de marcadores de células tronco com os subtipos moleculares de câncer de mama (luminal, basal e HER2 positivos). Essa correlação permite um estudo mais aprofundado da fisiopatogenia dos perfis moleculares do câncer de mama e o desenvolvimento de novas abordagens terapêuticas.
\end{abstract}

Palavras- chave: Câncer. Mama. Células tronco. Prognóstico. Perfil molecular.

\begin{abstract}
Breast cancer is the most common malignant disease among women. Most breast cancers are resulted from genetic and epigenetic alterations that may change cellular morphology and functions. Breast cancer tumorigenesis and its progression are caused by the accumulation of these genetic alterations that leads the gradual transition of the normal tissue to a malignant one. Besides these alterations, it is believed that the cancer can be originated from only one single cell that acquires the ability to proliferate indefinitely. These cells share some features with adult normal tissue stem cells and because of that they can be called tumor stem cells. Recent studies correlated the expression of stem cell markers with molecular subtypes of breast cancer (luminal, basal, HER2 positives). This correlation allows a deeper study of the physiopathogenesis of the molecular subtypes of breast cancer e the development of new therapeutic approaches.
\end{abstract}

Keywords: Cancer. Breast. Stem cell. Prognostic. Molecular profile.

\footnotetext{
* Departamento de Patologia e Medicina Legal, Faculdade de Medicina de Ribeirão Preto, Universidade de São Paulo, Ribeirão Preto, São Paulo 14049-900, Brasil.

Endereço: Departamento de Patologia e Medicina Legal, Faculdade de Medicina de Ribeirão Preto- Universidade de São Paulo, Avenida Bandeirantes 3900, 14049-900, Ribeirão Preto, São Paulo, Brasil.

E-mail: julianazanetti@usp.br

E-mail: arsilva@ fmrp.usp.br

${ }^{\dagger}$ Universidade Vale do Rio Verde (UninCor) - Três Corações - MG

E-mail: lucinei@yahoo.com 


\section{Introdução}

A glândula mamária é composta por vários tipos celulares que estabelecem entre si uma rede de interações responsável pelo desenvolvimento e fisiologia do órgão. Durante o desenvolvimento, a mama passa por uma série de transformações e alterações que determinam mudanças na morfologia e na expressão de diversas proteínas. A maioria destas proteínas pode ser identificada através da imuno-histoquímica. Sendo assim, podemos avaliar a expressão de cada uma delas nas diferentes etapas do desenvolvimento mamário. As diversas interações entre os tipos celulares e estas proteínas mantêm um microambiente responsável pela regulação das atividades celulares como, por exemplo: proliferação, sobrevivência, polaridade, diferenciação e capacidade de invasão. Um desequilíbrio nesse microambiente pode resultar no aparecimento de anomalias no desenvolvimento da glândula, doenças inflamatórias, alterações fibrocísticas, neoplasias malignas, dentre outros.

O câncer de mama é considerado uma doença geneticamente complexa caracterizada pelo acúmulo de diversas alterações genéticas e epigenéticas, expressão de marcadores tumorais, oncogenes, alterações em reguladores chaves do ciclo celular, presença de células tronco tumorais e/ou células progenitoras, entre outras. Essa doença também é caracterizada por apresentar subtipos moleculares que conferem às pacientes diferenças significativas quanto a fatores de prognóstico como sobrevida global e a sobrevida livre de doença. Todas estas alterações e expressões resultam em diferenças significativas quanto à resposta terapêutica e curso clínico da doença (GUSTERSON et al., 2005; RAKHA et al., 2010; WEIGELT et al., 2010).

\section{Epidemiologia do câncer de mama}

O câncer de mama é o segundo tipo de câncer mais frequente no mundo e o mais comum entre as mulheres. Segundo dados do American Cancer Society, em 2011, nos Estados Unidos, aproximadamente 207.090 mulheres serão diagnosticadas com a doença, sendo 54.010 previstos como carcinoma in situ e 39.840 óbitos.

No Brasil, a cada ano, $22 \%$ dos novos casos de câncer femininos correspondem ao câncer de mama (INCA- Instituto Nacional do Câncer, 2009). A distribuiç̧ão desses novos casos segundo a localização primária mostrase heterogênea entre Estados e capitais do país, porém, na região Sudeste o câncer de mama feminina é o mais incidente com aproximadamente 65 novos casos a cada 100 mil mulheres (Instituto Nacional do Câncer, 
2009). No Estado de Minas Gerais está previsto 4.250 novos casos de câncer de mama para cada 100 mil mulheres, sendo o segundo tipo de câncer que mais acomete a população desta região, perdendo apenas para o câncer de próstata com 5.350 casos para cada 100 mil homens.

A incidência do câncer de mama e as taxas de mortalidade aumentam com a idade. Segundo dados da American Cancer Society, no período de 2002 a 2006, a taxa de incidência do câncer de mama foi perto dos 97\% em mulheres acima de 40 anos de idade. Durante o mesmo ano, a média de idade no momento do diagnóstico foi de 61 anos. Quanto à etnia, mulheres brancas têm uma alta incidência de desenvolver o câncer de mama quando comparadas com mulheres afro-americanas (American Cancer Society. Breast Cancer Facts \& Figures 2009-2010).

\section{Fisiologia e microambiente mamário}

A mama normal é formada por um sistema de ductos ramificados divididos em dois grupos: a unidade terminal ducto lobular (UTDL) e os grandes ductos. A UTDL é a unidade funcional da mama e é formada basicamente por dois tipos celulares: uma camada única de células luminais (células colunares com capacidade de absorção e secreção) e uma camada única de células mioepiteliais (camada externa ou basal, com morfologia variável) (GUSTERSON et al., 2005). As células luminais são caracterizadas por seu fenótipo epitelial e expressão de citoqueratinas de baixo peso molecular $(7$, 8 e 18), proteínas relacionadas ao leite, antígeno epitelial específico (ESA), antígeno epitelial de membrana (EMA), mucinas (MUC1), dentre outros. As células mioepiteliais são caracterizadas pela expressão de citoqueratinas de alto peso molecular (5 e 14), $\alpha-6$ integrina, actina muscular lisa- $\alpha$ ( $\alpha$-SMA), metaloproteinases (como o CD10), entre outros (GUSTERSON et al., 2005; LÜ et al., 2009).

A relação entre estes tipos celulares e as proteínas aí expressas, forma uma complexa rede de interações responsável pelo desenvolvimento e funcionalidade do órgão. Esse microambiente pode exercer influência direta sobre as células modificando as propriedades de proliferação, sobrevivência, polaridade, diferenciação e invasão (POLYAK; KALLURI, 2010). Os processos de invasão e metástase, por exemplo, utilizam estratégias que envolvem mudanças no microambiente celular alterando a estrutura física de adesão das células e ativando proteases extracelulares (HANAHAN; WEINBERG, 2000). Os processos inflamatórios também podem contribuir para uma mudança neste microambiente, pois ocorre a ativação de células mesenquimais, 
fibroblastos, células endoteliais e imunes que secretam citocinas, fatores de crescimento, enzimas responsáveis pelo remodelamento do tecido, produção de citocinas associadas à senescência celular, sinalização pelo TGF- $\beta$ dentre outros fatores (MCDANIEL et al., 2006; SCHEDIN et al., 2007; KORKOLA \& GRAY, 2010). Sendo assim, a maioria dos tumores de mama, assim como os tumores em geral, são resultantes de alterações genéticas e epigenéticas que se acumulam nas células e que podem mudar a morfologia e a função das mesmas (DAIDONE et al., 2004; LOPEZGARCIA et al., 2010). Por isso, alterações neste microambiente podem ser tão significativas a ponto de possibilitar o desenvolvimento e a progressão de um tumor (POLYAK \& KALLURI, 2010).

Além destes, outros fatores influenciam no surgimento do câncer de mama tais como: desregulação dos receptores de estrógeno (que permitem o aumento da proliferação das células epiteliais mamárias) (NAKLES et al., 2011), problemas na checagem do ciclo celular, auto-suficiência nos fatores de crescimento (HANAHAN \& WEINBERG, 2000), amplificação de oncogenes e inativação de genes supressores de tumor (VAN DE VIJVER, 2000), erros na via de apoptose e inabilidade no controle da senescência celular fazem com que as células possam se reproduzir sem restrição, invadir tecidos locais e, por fim, estabelecer metástase à distância (RIBEIRO-SILVA et al., 2005). Portanto, a tumorigênese do câncer de mama e sua progressão são consideradas como sendo o resultado destes diversos processos no qual o acúmulo de todas estas alterações genéticas permite a transição gradual do tecido normal para o maligno.

\section{Marcadores de prognóstico no} câncer de mama

Entende-se por fator de prognóstico as características clínicas, patológicas e biológicas específicas de cada indivíduo e seus respectivos tumores que permitem prever a evolução clínica da doença e o tempo de sobrevida do paciente sem que este tenha recebido algum tipo de tratamento após o diagnóstico inicial (FUKUTOMI; AKASHITANAKA, 2002; ALLRED, 2005; LØNNING, 2007; GOBBI et al., 2008). Segundo Clark e colaboradores, estes fatores de prognóstico podem ser utilizados em três situações clínicas distintas: aquela cujo prognóstico do paciente é tão bom que nenhum tratamento após a cirurgia seria capaz de agregar mais benefícios, aquela em que o prognóstico do paciente é tão desfavorável com os tratamentos convencionais que há a necessidade de estabelecer outros mais agressivos; e finalmente aquela situação em que é possível indicar quais pacientes serão ou não beneficiados com uma terapêutica específica (CLARK et al., 1996). 
A utilização de marcadores de prognóstico no câncer de mama desenvolvido pelo Instituto Nacional de Saúde dos Estados Unidos é feita com base em seis fatores de prognóstico principais: acometimento de linfonodos axilares, subtipo histológico, tamanho do tumor, grau nuclear ou histológico, presença ou ausência de receptores hormonais e índice proliferativo (FUKUTOMI \& AKASHI-TANAKA, 2002; CIANFROCCA \& GOLDSTEIN, 2004).

Em contraste com os fatores de prognóstico, os fatores preditivos permitem, com base nos dados clínicos, patológicos e biológicos, direcionar tratamentos específicos e individualizados (GOBBI et al., 2008). Poucos marcadores são considerados exclusivamente como sendo de prognóstico, enquanto a maioria deles é considerada tanto de prognóstico quanto preditivo; como por exemplo, a super expressão do HER-2 e a inativação da p53 no câncer de mama (FUKUTOMI \& AKASHI-TANAKA, 2002).

\section{Marcadores tumorais avaliados pelo método imuno-histoquímico}

Grande parte dos materiais recebidos em um laboratório de Anatomia Patológica pode ser avaliada através da coloração de rotina hematoxilina-eosina (H\&E). Outras técnicas de avaliação também podem ser utilizadas, como a técnica de imunohistoquímica para a visualização de reações antígenos- anticorpos específicos. Geralmente a técnica de imuno-histoquímica é utilizada quando não é possível um diagnóstico preciso utilizando-se apenas a técnica de $\mathrm{H} \& \mathrm{E}$ (análise morfológica). Alguns marcadores são comumente utilizados nesta técnica, como por exemplo, os receptores hormonais (receptores de estrógeno e progesterona), marcadores de proliferação como o Ki67, marcadores do ciclo celular como a p53, marcadores de angiogênese como o fator de crescimento vascular endotelial (VEGF), dentre outros.

Os hormônios esteroidais possuem um papel muito importante no desenvolvimento da glândula mamária e na tumorigênese, agindo através de receptores nucleares localizados nas células alvo (CLARK et al., 2005). O estrógeno é um hormônio esteroidal importante no organismo feminino tanto para processos de proliferação, quanto para a sobrevivência celular. Estes tipos de receptores geralmente possuem uma organização estrutural muito semelhante entre si que consiste em um domínio hiper-variável N-terminal (AF-1), um domínio ligante do DNA e um domínio C-terminal (AF-2) (ZHOU et al., 1998).

Mais de $70 \%$ dos cânceres de mama expressam altos níveis de Receptores de Estrógeno (RE) e muitos destes tumores são dependentes deste para seu crescimento e progressão (FILLMORE et al., 2010). Além disso, a associação entre RE e a taxa de mortalidade nessa doença possui uma razão 
de risco. Esta razão em tumores RE positivos se mantém praticamente constante com o passar do tempo, enquanto que em tumores RE negativos esta razão é mais elevada no início do diagnóstico (quando comparados com os RE positivos) e após 7- 10 anos esta taxa diminui (BLOWS et al., 2010). Sendo assim, mulheres com RE positivos possuem maiores índices de sobrevida e melhor resposta a tratamentos hormonais.

Tanto os RE quanto os receptores de progesterona (RP) se localizam nas células luminais do epitélio das estruturas ductais e lobulares e apesar de ambos receptores coexistirem nas células luminais, estes dividem as células em RE positivos e RP negativos e vice- versa (CLARK et al., 2005). A presença de RE e RP servem, dentre outros motivos, como marcadores preditivos e de prognóstico (CIANFROCCA \& GOLDSTEIN, 2004).

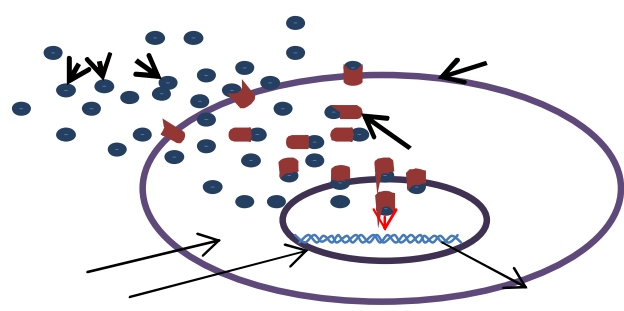

Figura 1: Receptor de estrógeno em célula mamária. Ao ser transportado para o núcleo, o estrógeno promove a transcrição de genes que irão influenciar o crescimento celular e promover sua sobrevivência culminando na progressão tumoral. Fonte: Juliana $\mathrm{S}$ Zanetti et al.
Outro marcador imuno-histoquímico bastante utilizado é o gene supressor de tumor TP53. Além da sua capacidade de supressor do tumor, o p53 pode regular o estresse oxidativo, a sobrevida celular, a invasão, a senescência celular, a angiogênese e a diferenciação celular (dentre outros inúmeros fatores) (VOUSDEN \& LANE, 2007). O p53 também tem sido utilizado como fator de prognóstico no câncer de mama e em carcinomas epidermóides (OLIVEIRA et al., 2010).

O Ki67 também é um marcador imuno-histoquímico utilizado como marcador (nuclear) de células em proliferação no câncer de mama (CLAYTON et al., 2004). Este tipo de câncer expressa altos níveis de Ki67 e embora isto ocorra, este ainda não é amplamente utilizado na rotina diagnóstica, pois não se sabe ainda como seus níveis podem influenciar nas decisões clínicas (CHEANG et al., 2009). Porém, Urruticoechea e colaboradores demonstraram eficácia no uso do Ki67 na rotina clínica como um marcador preditivo para taxa de crescimento do tumor e persistência da doença (URRUTICOECHEA et al., 2005).

O VEGF, marcador de crescimento angiogênico, é expresso tanto em condições fisiológicas quanto em condições patológicas e é responsável pela formação de novos vasos sanguíneos estimulando a proliferação, a diferenciação e a migração de células endoteliais (BAN et al., 2010). A primeira 
condição para que ocorra a angiogênese é a concentração de oxigênio nos tecidos locais e, o VEGF é conhecido por ser regulado pelo fator indutor da hipóxia $1 \alpha(\mathrm{HIF}-1 \alpha)$ e por estar super-expresso no câncer de mama (BLUFF et al., 2009).

\section{Células tronco tumorais}

Todos os tecidos no organismo humano adulto são derivados de células tronco com propriedades específicas que mantêm a integridade do tecido. Estas células tronco são conhecidas principalmente por sua capacidade de se auto-renovarem e se diferenciarem em outros tipos celulares que compõe o órgão que se encontram (OLIVEIRA et al., 2010). A teoria mais aceita sobre a etiopatogênese do câncer é que ele se origina de uma única célula que adquire a capacidade de se proliferar indefinidamente. Essas células compartilham algumas características com as células tronco do tecido adulto normal, por isso muitas vezes são denominadas células tronco tumorais (CARIATI \& PURUSHOTHAM, 2008). Acredita-se que as neoplasias malignas são resultados de mutações sequenciais que podem ocorrer como consequência de uma progressiva instabilidade genética e/ ou fatores ambientais (OLIVEIRA et al., 2010).
Com a expansão clonal, a maioria dessas células se diferencia para outros tipos celulares e perdem as suas características de células-tronco. Entretanto, parte dessas células permanece em seu estado original, e acredita-se que sejam essas células que mantém o crescimento tumoral e que determinam a resistência a diversos esquemas terapêuticos (PHILLIPS et al., 2006). Um dos grandes desafios da oncologia atual é identificar e estudar as características dessas células-tronco tumorais, também conhecidas como células iniciadoras tumorais (PONTI et al., 2005).

Células tumorais com características de células-tronco já foram identificadas em diversos tipos de cânceres, incluindo tumores de cérebro, de mama, de próstata e de pele (AL-HAJJ et al., 2003; COLLINS et al., 2005). No câncer de mama, as células neoplásicas com características de célulastroco mais estudadas são aquelas que expressam fortemente o CD44 e que tem expressão baixa ou ausente de CD24 (imunofenótipo CD44+CD24-) (ABRAHAM et al., 2005). Essas células neoplásicas CD44+CD24- são 100 vezes mais tumorigênicas do que as células que não exibem esse imunofenótipo (AL-HAJJ et al., 2003). Células com imunofenótipo CD44+CD24- estão presentes em 22 a $31 \%$ dos carcinomas mamários humanos. Esses carcinomas são agressivos, apresentando alta 
taxa de metástases, sobretudo metástases ósseas (ABRAHAM et al., 2005).

Além do CD44 e do CD24, outros marcadores também foram associados a células-tronco e células progenitoras do tecido mamário. Entre esses marcadores destacam-se MUC1, CD10 e ESA (STINGL, 2009).

A MUC1 é um membro da família das mucinas, que são proteínas de membrana glicosiladas. A mucina 1 é uma proteína heterodimérica transmembrana com uma subunidade citoplasmática $\mathrm{C}$ terminal (MUC1-C) (HUANG et al., 2010; MACDERMED et al., 2010) que é responsável pela interação com receptores de fatores de crescimento e efetores como $\beta$ catenina, IKB quinase e p53 que regulam o ciclo, o crescimento e a morte celular (HUANG et al., 2010). A superexpressão, a localização intracelular aberrante e alterações na glicosilação da MUC1 estão associadas ao desenvolvimento do carcinoma de mama (YANG et al., 2010), pois há perda de polaridade celular levando à perda da adesão célula- célula e célula- matriz extracelular (ABBA et al., 2006). Além disso, a MUC1 está diretamente relacionada com diversas vias de sinalização celular como a via da AKT (phosphoinositol-3 kinase), podendo ativar esta como parte de respostas antiapoptóticas (HATTRUP \& GENDLER, 2006). Como a MUC1 encontra-se superexpressa em cerca de 90\% dos carcinomas mamários, a imunoterapia específica contra essa proteína é uma opção terapêutica promissora no tratamento deste tipo de câncer, no entanto essa superexpressão também confere resistência à morte celular induzida pelo estresse quando expostas a agentes anticancerígenos genotóxicos (HATTRUP \& GENDLER, 2006; MACDERMED et al., 2010).

O CD10, também conhecido como Neprilysin e CALLA (do inglês "common acute lymphoblastic leukemia antigen") é uma metaloproteinase zinco dependente (glicoproteína de superfície) de 90 a 110 kd e é localizado no cromossomo 3 na região q2127 que quebra ligações peptídicas no lado hidrofóbico de aminoácidos (PAPANDREOU \& NANUS, 2010). Degrada, entre outros, o peptídeo beta amilóide, cuja deposição no sistema nervoso central é considerada uma das causas da doença de Alzheimer (HERSH \& RODGERS, 2008). CD10 foi identificado em diversos tipos celulares normais como células mioepiteliais da mama (que expressa CD10 na membrana lateral) (MORITANI et al., 2002; WAGONER et al., 2007), glândulas salivares, células ductais prostáticas, células glomerulares do rim, células estromais do endométrio dentre vários outros tecidos (TSE et al., 2005). Essa metaloproteinase foi identificada também em células metaplásicas apócrinas e adenocarcinoma in situ (MORITANI et al., 2002), células de mama neoplásicas, carcinomas, gliomas, 
melanomas, dentre outros (TSE et al., 2005). Em alguns tipos de câncer, como no carcinoma metastático da mama e no melanoma, existe super expressão do CD10, enquanto que em outros cânceres, como o carcinoma de pulmão, sua expressão está reduzida (KRISTIANSEN et al., 2002; SMOLLICH et al., 2007).

Dentre os substratos do CD10 há uma gama de pequenos peptídeos, como bombesina, fator natriurético atrial (WAGONER et al., 2007) endotelina-1 e fator de crescimento do fibroblasto (PAPANDREOU \& NANUS, 2010). O domínio citoplasmático do CD10 interage com diversas proteínas como Lyn quinase e PTEN (tensin homolog protein). A PTEN endógena da membrana celular é recrutada pelo CD10 e o aumento da atividade fosfatase da PTEN resulta em uma queda constitutiva da atividade do AKT. Sendo assim, células que perdem a metilação do CD10 permitem que ocorra um aumento da migração, crescimento e sobrevivência celular contribuindo para o desenvolvimento e progressão neoplásica (PAPANDREOU \& NANUS, 2010). Segundo Wagoner e cols (2007) o CD10 geralmente reduz a resposta celular à peptídeos hormonais e a quantidade de CD10 expresso parece se relacionar com a taxa de crescimento celular e em células com neoplasias malignas ocorre um aumento do índice proliferativo (WAGONER et al., 2007).
O ESA (do inglês "epithelial specific antigen") tem sido considerado um marcador de células tronco tumorais de diversas neoplasias, incluindo os carcinomas de mama, próstata e pâncreas (LI et al., 2007). No câncer de mama o ESA é um marcador de células tronco em tumores RE positivos, e, além disso, pode estar associado com metástase linfonodal e recorrência tumoral (LIU et al., 2009). Essa proteína pode ser encontrada tanto em células mioepiteliais quanto em células luminais e células que expressam ESA+ podem indicar que estas são células tronco ou progenitoras na mama (CLAYTON et al., 2004). Há alguns estudos que mostram evidências de células progenitoras epiteliais mamárias bi-potentes em tecido mamário adulto normal que apresentam ESA e MUC1 e quando reproduzidos in vitro originam clones que expressam somente marcadores luminais (CARIATI \& PURUSHOTHAM, 2008). Células que expressam ESA+/ $\mathrm{MUC1}^{-/ \mathrm{fraco} /}$ $\mathrm{CD} 0^{+/ \text {fraco }}$ podem gerar clones de ambas as linhagens (STINGL et al., 1998). O epitélio mamário é composto fundamentalmente de dois tipos celulares: epitélio basal (mioepitelial) e epitélio luminal (A e B). Cada tipo celular é capaz de apresentar fenótipo de carcinoma invasivo com características histológicas diferentes e também expressar receptores diferentes (GUSTERSON et al., 2005). 
Segundo Clayton e cols (2004) em cultura de células mamárias, as células luminais gradativamente se convertem em células mioepiteliais mostrando que estas últimas são derivadas de precursores luminais (CLAYTON et al., 2004). No tecido mamário, a combinação dos imunofenótipos com MUC1, CD10 e ESA, por exemplo, podem levar à diferenciações celulares diferentes como: células progenitoras MUC1+/CD10-/ESA+ se diferenciam para células luminais, células progenitoras MUC1/CD10+/ESA- se diferenciam para células mioepiteliais e células progenitoras MUC1/CD10+/ESA+ se diferenciam para ambas as linhagens (STINGL et al., 1998). Porém, a relação destes imunofenótipos com prognóstico e terapêutica ainda não está bem estabelecido.

\section{Perfis Moleculares:}

O câncer de mama é uma doença heterogênea composta por diferentes achados biológicos, subtipos histológicos e comportamento clínico que juntos determinam o prognóstico da paciente (TURNER \& REIS-FILHO, 2006; WEIGELT et al., 2010). Os carcinomas mamários podem ser divididos em pelo menos cinco subtipos conforme seus perfis moleculares: luminal A, luminal B, normal-símile, HER2+e basal (DABBS et al., 2006; NIELSEN et al., 2004;
PEROU et al., 2000; SORLIE et al., 2003;). Existem diferenças significativas entre a sobrevida global e a sobrevida livre de doença entre esses subtipos. Os piores prognósticos estão associados ao subtipo basal e ERBB2+ (TURNER \& REIS-FILHO, 2006). Perou e colaboradores observaram que as neoplasias que não expressam receptor de estrógeno (RE negativo) representam um grupo clinicamente diferente daquelas neoplasias que expressam este receptor (RE positivo). Através de expressões gênicas semelhantes dentro destes grupos RE positivo e RE negativo, os autores definiram os quatro fenótipos de carcinoma mamário (PEROU et al., 2000).

As neoplasias RE negativas foram divididas em HER2+ e fenótipo basal (PEROU et al., 2000). O fenótipo HER2+ é caracterizado pela amplificação de vários genes, incluindo o HER2/neu, o GRB7 e o TRAP100 (SORLIE et al., 2001). Estes tumores exibem alta taxa de mutação no gene TP53 (40-80\%) e geralmente são carcinomas grau 3 e linfonodo positivos (BRENTON et al., 2005). Estes tumores estão associados a um péssimo prognóstico independente do grau, e quando o HER2 está amplificado, o tumor apresenta uma alta atividade mitótica, alto grau de pleomorfismo nuclear e uma associação com comedo necrose e carcinoma ductal in situ (HANBY, 2005).

O sistema ductal mamário engloba domínios com diferentes morfologias e 
funções. A camada de células basais é morfologicamente heterogênea e as células aparecem de forma fusiforme ou cuboidais dependendo das variações da estrutura dos ductos mamários ou das variações hormonais ou na menopausa (GUSTERSON et al., 2005). O uso do termo "basal" é dado a essas células neoplásicas deste tipo tumoral, pois estas células expressam genes usualmente expressos em células basais e/ou mioepiteliais da mama normal (TURNER \& REIS-FILHO, 2006) como as citoqueratinas de alto peso molecular (VAN DE VIJVER, 2000). Os carcinomas basais são caracterizados por um mau prognóstico (RAKHA et al., 2007) e alto grau histológico. Em 1982 Moll e colaboradores trabalharam com cultura de células do epitélio normal e tumorais e identificaram dois principais grupos de câncer de mama baseados na expressão de citoqueratinas, sendo assim, esse fenótipo é caracterizado pela alta expressão de citoqueratinas basais tais como as citoqueratinas 5 e 17 (GUSTERSON et al., 2005; TURNER \& REIS-FILHO, 2006; VAN DE VIJVER, 2000). Nestes tumores, o índice mitótico é alto e o pleomorfismo nuclear é acentuado (CAREY et al., 2006). Estes tumores são geralmente negativos para receptores de estrógeno e progesterona (Korsching et al., 2002) e HER2 (DABBS et al., 2006) e estão associados a expressão de genes mutantes para determinados marcadores, como o p53, TP53 (TURNER \&
REIS-FILHO, 2006) e o receptor do fator de crescimento epitelial (Korsching et al., 2002), além disso, expressam CK 5/6, CK 14, CK17, (DABBS et al., 2006) vimentina, HER1 (DABBS et al., 2006), p-caderina e caveolina 1 (TURNER \& REIS-FILHO, 2006). Carcinomas com o imunofenótipo basal correspondem a $17-37 \%$ dos carcinomas mamários (FOULKES, 2003; NIELSEN et al., 2004; SORLIE et al., 2003).

Atualmente muito se discute a respeito do perfil triplo-negativo que de todos os perfis é o que possui o comportamento clínico mais agressivo e é encontrado em aproximadamente $11 \%$ dos carcinomas invasivos. Esse perfil é definido como sendo negativo para os receptores hormonais (RE e RP) e para o HER2 (THIKE et al., 2010).

O fenótipo luminal foi denominado dessa forma porque as neoplasias RE positivas expressavam outros genes que também são expressos por células luminais da mama, sendo assim, pode-se supor que os carcinomas de mama RE positivo poderiam ter origem a partir desse tipo celular (PEROU et al., 2000). O fenótipo luminal é o subtipo mais comum, correspondendo aos carcinomas mamários positivos para os receptores de estrógeno. Estes carcinomas expressam as citoqueratinas 8 e 18, além de genes associados com a ativação dos receptores de estrógeno, como a LIV1 e a ciclina D1 (PEROU et al., 2000). Os carcinomas de 
imunofenótipo luminal geralmente são bem diferenciados (grau 1 Nottingham) e menos de $20 \%$ apresentam mutações no gene TP53

(SORLIE et al., 2003).

Os carcinomas de imunofenótipo luminal podem ser divididos em luminal A e luminal B. Embora ambos expressem receptores hormonais, o subtipo luminal A tem uma expressão maior de genes associados aos receptores de estrógeno e uma expressão menor de genes proliferativos do que os carcinomas do subtipo luminal B (SORLIE et al., 2003). Pacientes com carcinomas luminais A têm melhor sobrevida global em comparação às pacientes com carcinomas luminal B (CHANG et al., 2005).

\section{Conclusão}

Como apresentado, o câncer de mama é uma doença complexa que engloba diversas alterações genéticas e epigenéticas, além disso, mudanças no microambiente mamário podem contribuir para o desenvolvimento de carcinomas. Como cada tipo de carcinoma possui uma determinada característica, é preciso realizar uma abordagem específica para cada um deles a fim de direcionar o diagnóstico e o tratamento a serem utilizados. Além disso, essa subdivisão molecular permite tratar as pacientes em esquemas mais individualizados. Outro ponto importante deste trabalho foi a discussão sobre células tronco e células progenitoras que podem possivelmente ser utilizadas como alvos terapêuticos.

\section{Referências}

ABBA, M. C.; NUNEZ, M. I.; COLUSSI, A. G.; et al. GATA3 protein as a MUC1 transcriptional regulator in breast cancer cells. Breast cancer research : BCR, v. 8, n. 6, p. R64, 2006.

ABRAHAM, B. K.; FRITZ, P.; MCCLELLAN, M.; et al. Prevalence of CD44+/CD24-/low cells in breast cancer may not be associated with clinical outcome but may favor distant metastasis. Clinical cancer research, v. 11, n. 3, p. 1154-9, 2005.

AL-HAJJ, M.; WICHA, M. S.; BENITOHERNANDEZ, A.; MORRISON, S. J.; CLARKE, M. F. Prospective identification of tumorigenic breast cancer cells. Proceedings of the National Academy of Sciences of the United States of America, v. 100, n. 7, p. 3983-8, 2003.

ALLRED, D. C. Assessment of Prognostic and Predictive Factors in Breast Cancer by Immunohistochemistry ER. Breast, p. 20052006, 2005.

BAN, H. S.; UNO, M.; NAKAMURA, H. Suppression of hypoxia-induced HIF-1alpha accumulation by VEGFR inhibitors: Different profiles of AAL993 versus SU5416 and KRN633. Cancer letters, v. 296, n. 1, p. 1726, 2010.

BLOWS, F. M.; DRIVER, K. E.; SCHMIDT, M. K.; et al. Subtyping of breast cancer by immunohistochemistry to investigate a relationship between subtype and short and long term survival: a collaborative analysis of data for 10,159 cases from 12 studies. PLoS medicine, v. 7, n. 5, p. e1000279, 2010.

BLUFF, J. E.; MENAKURU, S. R.; CROSS, $\mathrm{S} \mathrm{S}$; et al. Angiogenesis is associated with the 
onset of hyperplasia in human ductal breast disease. British journal of cancer, v. 101, n. 4, p. 666-72, 2009.

BRENTON, J.D. et al. Molecular classification and molecular forecasting of breast cancer: ready for clinical application? J Clin Oncol. v.23, p.7350-60, 2005.

CAREY, L. A; PEROU, CHARLES M; LIVASY, C. A; et al. Race, breast cancer subtypes, and survival in the Carolina Breast Cancer Study. JAMA : the journal of the American Medical Association, v. 295, n. 21, p. 2492-502, 2006.

CARIATI, M.; PURUSHOTHAM, A D. Stem cells and breast cancer. Histopathology, $v$. 52, n. 1, p. 99-107, 2008.

CHANG, H. Y.; NUYTEN, D. S. A; SNEDDON, J. B.; et al. Robustness, scalability, and integration of a woundresponse gene expression signature in predicting breast cancer survival.

Proceedings of the National Academy of Sciences of the United States of America, v. 102, n. 10, p. 3738-43, 2005.

CHEANG, M. C. U.; CHIA, S. K.; VODUC, D.; et al. Ki67 index, HER2 status, and prognosis of patients with luminal B breast cancer. Journal of the National Cancer Institute, v. 101, n. 10, p. 736-50, 2009.

CIANFROCCA, M.; GOLDSTEIN, L. Prognostic and Predictive Factors in EarlyStage Breast Cancer. Breast, v. 9, p. 606-616, 2004.

CLARKE, R.B., HOWELL, A., POTTEN, C.S., ANDERSON, E. Dissociation between steroid receptor expression and cell proliferation in the human breast. Cancer Res. v.57, p. 4987-4991,1997.

CLAYTON, H.; TITLEY, I.; VIVANCO, M. DM. Growth and differentiation of progenitor/stem cells derived from the human mammary gland. Experimental cell research, v. 297, n. 2, p. 444-60, 2004.
COLLINS, A. T.; BERRY, P. A; HYDE, C.; STOWER, M. J.; MAITLAND, N. J.

Prospective identification of tumorigenic prostate cancer stem cells. Cancer research, v. 65, n. 23, p. 10946-51, 2005.

DABBS, D.; CHIVUKULA, M.; CARTER, G.; BHARGAVA, R. Basal phenotype of ductal carcinoma in situ: recognition and immunohistologic profile. Modern pathology : an official journal of the United States and Canadian Academy of Pathology, Inc, v. 19, n. 11, p. 1506-11, 2006.

DAIDONE, M. G.; PARADISO, A.; GION, M.; et al. Biomolecular features of clinical relevance in breast cancer. European journal of nuclear medicine and molecular imaging, v. 31 Suppl 1, n. June, p. S3-14, 2004.

EL-SAYED, M. E.; GREEN, A R.; PAISH, E. C.; LEE, A H. S.; ELLIS, I O, with Rakha. Breast carcinoma with basal differentiation: a proposal for pathology definition based on basal cytokeratin expression. Histopathology, v. 50, n. 4, p. 434-8, 2007.

FILLMORE, C. M.; GUPTA, P. B.; RUDNICK, J. A; et al. Estrogen expands breast cancer stem-like cells through paracrine FGF/Tbx 3 signaling. Proceedings of the National Academy of Sciences of the United States of America, p. 1-6, 2010.

FOULKES, W. D. Germline BRCA1 Mutations and a Basal Epithelial Phenotype in Breast Cancer. CancerSpectrum Knowledge Environment, v. 95, n. 19, p. 1482-1485, 2003.

FUKUTOMI, T.; AKASHI-TANAKA, S. Prognostic and predictive factors in the adjuvant treatment of breast cancer. Breast cancer (Tokyo, Japan), v. 9, n. 2, p. 95-9, 2002.

GOBBI, H.; ROCHA, R. M.; NUNES, C. B. Predictive factors of breast cancer evaluated 
by immunohistochemistry. Jornal Brasileiro de Patologia e Medicina Laboratorial, v. 44, n. 2, p. 131-140, 2008.

GUSTERSON, B.; ROSS, D T; HEATH, V J; STEIN, T. Basal cytokeratins and their relationship to the cellular origin and functional classification of breast cancer.

Breast cancer research : BCR, v. 7, n. 4, p. 143-8, 2005.

HANAHAN, D.; WEINBERG, R. A. The Hallmarks of Cancer. Cell, v. 100, p. 57-70, 2000 .

HANBY, A M. Aspects of molecular phenotype and its correlations with breast cancer behaviour and taxonomy. British journal of cancer, v. 92, n. 4, p. 613-7, 2005.

HATTRUP, C. L.; GENDLER, SANDRA J. MUC1 alters oncogenic events and transcription in human breast cancer cells. Breast cancer research : BCR, v. 8, n. 4, p. R37, 2006.

HERSH, L.B.; Rodgers, D.W. Neprilysin and amyloid beta peptide degradation. Curr

Alzheimer Res. 2008;5:225-31.

HUANG, L.; LIAO, X.; BECKETT, M.; et al. MUC1-C Oncoprotein Interacts Directly with ATM and Promotes the DNA damage response to ionizing radiation., v. 1, n. 3, p. 239-250, 2010.

KORKOLA, J.; GRAY, J. W. Breast cancer genomes--form and function. Current opinion in genetics \& development, v. 20, n. 1, p. 4-14, 2010.

KORSCHING, E. et al. Cytogenetic alterations and cytokeratin expression patterns in breast cancer: integrating a new model of breast differentiation into cytogenetic pathways of breast carcinogenesis. Lab Invest. v.82, p.1525-33, 2002.

KRISTIANSEN, G. et al. CD10 expression in non-small cell lung cancer. Anal Cell Pathol. v.24, p.41-6, 2002.
LI, C.; HEIDT, D. G.; DALERBA, P.; et al. Identification of pancreatic cancer stem cells. Cancer research, v. 67, n. 3, p. 1030-7, 2007.

LIU, Q.; JI-GUANG, L.; XIN-YU, Z.; FENG, J.; HUI-TING, D. Expression of 133, PAX2, ESA and GPR30 in invasive ductal breast carcinomas. Chinese Medical Journal, v. 122, n. 2006, p. 2763-2769, 2009.

LOPEZ-GARCIA, M. A; GEYER, F. C.; LACROIX-TRIKI, M.; MARCHIÓ, C.; REIS-FILHO, J. S. Breast cancer precursors revisited: molecular features and progression pathways. Histopathology, v. 57, n. 2, p. 171-92, 2010.

LØNNING, P E. Breast cancer prognostication and prediction: are we making progress? Annals of oncology : official journal of the European Society for Medical Oncology / ESMO, v. 18 Suppl 8, n. Supplement 8, p. viii3-7, 2007.

LÜ, X.; LI, H.; XU, K.; NESLAND, J. M.; SUO, Z. MUC-1-/ESA+ progenitor cells in normal, benign and malignant human breast epithelial cells. Histology and histopathology, v. 24, n. 11, p. 1381-90, 2009.

MACDERMED, D. M.; KHODAREV, N. N.; PITRODA, S. P.; et al. MUC1-associated proliferation signature predicts outcomes in lung adenocarcinoma patients. BMC medical genomics, v. 3, p. 16, 2010.

MCDANIEL, S. M.; RUMER, K. K.; BIROC, S. L.; et al. Remodeling of the mammary microenvironment after lactation promotes breast tumor cell metastasis. The American journal of pathology, v. 168, n. 2, p. 608-20, 2006.

MORITANI, S.; KUSHIMA, R.; SUGIHARA, H.; et al. Availability of CD10 immunohistochemistry as a marker of breast myoepithelial cells on paraffin sections.

Modern pathology : an official journal of 
the United States and Canadian Academy of Pathology, Inc, v. 15, n. 4, p. 397-405, 2002.

NAKLES, R. E.; SHIFFERT, M. T.; DÍAZCRUZ, E. S.; et al. Altered AIB1 or AIB1 $\Delta 3$ Expression Impacts ER $\alpha$ Effects on Mammary Gland Stromal and Epithelial Content. Molecular endocrinology (Baltimore, Md.), v. 25, p. 1-15, 2011.

NIELSEN, T. O.; HSU, F. D.; JENSEN, K.; et al. Immunohistochemical and clinical characterization of the basal-like subtype of invasive breast carcinoma. Clinical cancer research : an official journal of the American Association for Cancer Research, v. 10, n. 16, p. 5367-74, 2004.

OLIVEIRA, L. R.; JEFFREY, S.; RIBEIROSILVA, A. Stem cells in human breast cancer. Histology and histopathology, v. 25, n. 3, p. 371-85, 2010.

OLIVEIRA, L. R.; OLIVEIRA-COSTA, J. P.; ARAÚJO, I.; et al. Cancer stem cell immunophenotypes in oral squamous cell carcinoma Cancer stem cell

immunophenotypes in oral squamous cell carcinoma. J Oral Pathol Med, v. 40, n. 2, p. 135-42, 2011.

PAPANDREOU, C. N.; NANUS, D. M. Is methylation the key to CD10 loss? Journal of pediatric hematology/oncology: official journal of the American Society of Pediatric Hematology/Oncology, v. 32, n. 1, p. 2-3, 2010.

PEROU, C M; SØRLIE, T; EISEN, M. B.; et al. Molecular portraits of human breast tumours. Nature, v. 406, n. 6797, p. 747-52, 2000.

PHILLIPS, T. M.; MCBRIDE, W. H.; PAJONK, F. The response of CD24(/low)/CD44+ breast cancer-initiating cells to radiation. Journal of the National Cancer Institute, v. 98, n. 24, p. 1777-85, 2006.

POLYAK, K.; KALLURI, R. The Role of the Microenvironment in Mammary Gland
Development and Cancer. Cold Spring Harbor perspectives in biology, 2010.

PONTI, D.; COSTA, A.; ZAFFARONI, N.; et al. Isolation and in vitro propagation of tumorigenic breast cancer cells with stem/progenitor cell properties. Cancer research, v. 65, n. 13, p. 5506-11, 2005.

RAKHA, E. A; REIS-FILHO, J. S.; ELLIS, IAN O. Combinatorial biomarker expression in breast cancer. Breast cancer research and treatment, v. 120, n. 2, p. 293-308, 2010.

RIBEIRO-SILVA, A; BECKER DE MOURA, H.; RIBEIRO DO VALE, F.; ZUCOLOTO, S. The differential regulation of human telomerase reverse transcriptase and vascular endothelial growth factor may contribute to the clinically more aggressive behavior of p63-positive breast carcinomas. The International journal of biological markers, v. 20, n. 4, p. 227-34, 2005.

SCHEDIN, P.; O'BRIEN, J.; RUDOLPH, M.; STEIN, TORSTEN; BORGES, V. Microenvironment of the involuting mammary gland mediates mammary cancer progression. Journal of mammary gland biology and neoplasia, v. 12, n. 1, p. 71-82, 2007.

Smollich, M. et al. On the role of endothelinconverting enzyme-1 (ECE-1) and neprilysin in human breast cancer. Breast Cancer Res Treat. 2007;106:361-9.

SORLIE T., PEROU C.M., TIBSHIRANI R., et al. Gene expression patterns of breast carcinomas distinguish tumor subclasses with clinical implications. Proc Natl Acad Sci USA. v.98, p.10869-74, 2001.

SORLIE, T.; TIBSHIRANI, R.; PARKER, J.; et al. Repeated observation of breast tumor subtypes in independent gene expression data sets. Proceedings of the National Academy of Sciences of the United States of America, v. 100, n. 14, p. 8418-23, 2003. 
STINGL, J. Detection and analysis of mammary gland stem cells. Journal of Pathology, The, , n. October 2008, p. 229241, 2009.

STINGL, J.; EAVES, C. J.; KUUSK, U.; EMERMAN, J. T. Phenotypic and functional characterization in vitro of a multipotent epithelial cell present in the normal adult human breast. Differentiation; research in biological diversity, v. 63 , n. 4, p. 201-13, 1998.

TSE, G. M. K.; TSANG, A K. H.; PUTTI, T. C.; et al. Stromal CD10 expression in mammary fibroadenomas and phyllodes tumours. Journal of clinical pathology, v. 58, n. 2, p. 185-9, 2005.

TURNER, N.; REIS-FILHO, J. Basal-like breast cancer and the BRCA1 phenotype. Oncogene, v. 25, n. 43, p. 5846-53, 2006.

URRUTICOECHEA, A.; SMITH, I. E.; DOWSETT, M. Proliferation marker Ki-67 in early breast cancer. Journal of clinical oncology : official journal of the American Society of Clinical Oncology, v. 23, n. 28, p. 7212-20, 2005.

VAN DE VIJVER, M. Genetic alterations in breast cancer. Current Diagnostic

Pathology, v. 6, n. 4, p. 271-281, 2000.

VOUSDEN, K. H.; LANE, D. P. P53 in Health and Disease. Nature reviews.

Molecular cell biology, v. 8, n. 4, p. 275-83, 2007.

WAGONER, J.; KEEHN, C.; MORGAN, M. B. CD-10 immunostaining differentiates superficial basal cell carcinoma from cutaneous squamous cell carcinoma. The

American Journal of dermatopathology, v. 29, n. 6, p. 555-8, 2007.

WEIGELT, B.; GEYER, F. C.; REIS-FILHO, J. S. Histological types of breast cancer: how special are they? Molecular oncology, v. 4, n. 3, p. 192-208, 2010a. Elsevier B.V.
YANG, D. S.; PARK, K. H.; WOO, O. H.; et al. Association of a vascular endothelial growth factor gene $936 \mathrm{C} / \mathrm{T}$ polymorphism with breast cancer risk: a meta-analysis.

Breast cancer research and treatment, 2010.

ZHOU, X.; DESOUZA, M. M.; JULIAN, J.; GENDLER, S J; CARSON, D. D. Estrogen receptor does not directly regulate the murine Muc-1 promoter. Molecular and cellular endocrinology, v. 143, n. 1-2, p. 65-78, 1998. 